\title{
PAPO DE MULHER NA FRATERNIDADE: RELATO DE EXPERIÊNCIA DE EXTENSÃO UNIVERSITÁRIA EM PROMOÇÃO EM SAÚDE MENTAL ${ }^{1}$
}

Lucia Cristina dos Santos Rosa² Sofia Laurentino Barbosa Pereira ${ }^{3}$

\section{RESUMO}

Este artigo tem como objetivo analisar e caracterizar os aspectos inovadores do projeto de extensão "Ativar a potência da família na promoção em saúde mental" realizado por docentes do departamento de Serviço Social da Universidade Federal do Piauí na Associação "Fraternidade - O amor é a resposta" em Teresina-PI, a partir de um relato de experiência das ações do projeto, que foram iniciadas em março de 2019 e, desde então, realizam-se atividades em grupos com famílias, todas as quartas-feiras. A Associação Fraternidade é uma Organização Não Governamental, que atua em uma comunidade vulnerável, conhecida popularmente como Vila Ferroviária, em que o tráfico de drogas e o consumo abusivo de substâncias psicoativas tem uma presença marcante. Nesse sentido, a relevância do projeto se dá ao contribuir com ações de promoção em saúde mental, na perspectiva de fortalecer laços familiares e ampliar recursos comunitários na produção de cuidado de crianças, adolescentes e jovens, em contexto de vulnerabilidades, através de grupo com familiares, preenchendo uma lacuna assistencial e teórica junto às famílias.

Palavras-Chave: Família. Saúde Mental. Promoção em Saúde.

\section{INTRODUÇÃO}

Este artigo tem como objetivo analisar e caracterizar os aspectos inovadores do projeto de extensão "Ativar a potência da família na promoção em saúde mental" realizado por docentes do departamento de Serviço Social da Universidade Federal do Piauí na Associação "Fraternidade - O amor é a resposta" em Teresina-PI, a partir de um relato de experiência das ações do projeto, que foram iniciadas em março de 2019 e, desde então, realizam-se atividades em grupos com famílias, todas as quartas-feiras.

\footnotetext{
${ }^{1}$ Trabalho apresentado no Congresso Brasileiro Ciência e Sociedade (CBCS 2019), promovido pelo Centro Universitário Santo Agostinho, de 03 a 05 de outubro de 2019, em Teresina-PI.

${ }^{2}$ Doutora em Serviço Social, Docente do Programa de Pós-Graduação em Políticas Públicas e do Departamento de Serviço Social da Universidade Federal do Piauí (UFPI), luciacsrosa@ gmail.com

${ }^{3}$ Doutora em Políticas Públicas (UFRJ), Docente do Programa de Pós-Graduação em Políticas Públicas e do Departamento de Serviço Social da Universidade Federal do Piauí (UFPI), sofialaurentino@ ufpi.edulBEN: 978-65-80968-11-4
} DOI: $10.17648 /$ cbcs-2019-110642 
ANAIS CBCS 2019 | 3 a 5 de outubro de 2019 | Centro Universitário Santo Agostinho - Teresina - P

A extensão universitária, juntamente com o ensino e a pesquisa, compõem o tripé que constitui o eixo fundamental do ensino superior no Brasil, sendo um processo interdisciplinar, educativo, cultural, científico e político que promove a interação transformadora entre Universidade e outros setores da sociedade. Assim, a extensão reafirma o papel de transformação social da Universidade, que deve ser voltada para os interesses e necessidades da maioria da população e propiciadora do desenvolvimento social e regional, assim como para o aprimoramento das políticas públicas (FORPROEX, 2012).

Segundo a Resolução № 085/18, da Universidade Federal do Piauí - UFPI, a extensão deve ser direcionada à promoção de interação transformadora entre universidade e os demais segmentos da sociedade, possuindo cunho educativo, social e político.

Nessa direção, o projeto de extensão "Ativar a potência da família na promoção em saúde mental", cadastrado na Pró-Reitoria de Extensão e Cultura - PREXC da Universidade Federal do Piauí e vinculado ao Departamento de Serviço Social, tem por objetivos: promover ações socioeducativas na perspectiva de ativar a potência da família na promoção de ações em prol da saúde mental; constituir espaços para a construção de metodologias de trabalho social com a família e de ações interdepartamentais no âmbito da UFPI; explorar as configurações familiares na realidade atual e como o desenho da família repercute nos recursos em prol da promoção da saúde mental; caracterizar os direitos da e na família, a partir de seus diferentes segmentos e desafios identificados; identificar os fatores de proteção e risco para o consumo de substâncias psicoativas/saúde mental nas relações familiares; analisar a relação Estado/política social e família.

A Associação "Fraternidade - O amor é a resposta" é uma Organização Não Governamental, que existe desde 2007 e atua em uma comunidade vulnerável, conhecida popularmente como Vila Ferroviária, situada na cidade de Teresina, em que o tráfico de drogas e o consumo abusivo de substâncias psicoativas têm uma presença marcante, realizando atividades a partir da metodologia do Tratamento Comunitário, na perspectiva de fortalecer as ações comunitárias em prol de ações de prevenção ao consumo abusivo de substâncias psicoativas. 
ANAIS CBCS 2019 | 3 a 5 de outubro de 2019 | Centro Universitário Santo Agostinho - Teresina - P

A entidade concentrou suas ações na análise situacional dos problemas em saúde local e nas ações com o público infanto juvenil, com parca extensão à família e aos familiares desse segmento, que, no geral, acompanhava suas crianças para as atividades promovidas pela instituição, sobretudo: ballet; judô e skate.

O projeto de extensão teve início a partir de lacuna de ações voltadas para as famílias da região, identificada por dirigentes da Associação Fraternidade. Nesse sentido, a relevância do referido projeto se dá ao contribuir com ações de promoção em saúde mental, na perspectiva de fortalecer laços familiares e ampliar recursos comunitários na produção de cuidado de crianças, adolescentes e jovens, em contexto de vulnerabilidades, através de grupo com familiares, preenchendo uma lacuna assistencial e teórica junto às famílias.

\section{METODOLOGIA (Ou MATERIAL E MÉTODOS)}

Para atingir os objetivos propostos no projeto original de extensão, foi desenvolvida a metodologia qualitativa, pois teve por base as crenças, os valores, as percepções e as opiniões do grupo, adotando-se técnicas ativas, principalmente dinâmicas de grupo e a problematização, tal como proposto por Paulo Freire no livro, Pedagogia do Oprimido (1987), para fomentar a participação e o engajamento dos participantes.

Para a composição do grupo inicial, houve convite aos familiares que se dirigiam à Associação "Fraternidade - o amor é a resposta", às quartas feiras, a partir das 18:00hs, no início do mês de março de 2019, com o objetivo de levar crianças para as aulas de ballet ou judô. O grupo se compôs a partir dos familiares que ficavam aguardando o termino das aulas de seus filhos, sobrinhos ou netos, cada reunião tendo em média uma hora, tempo considerado ideal para manter o interesse grupal.

O grupo passou a se reunir toda quarta feira, a partir das 18hs, em sala da própria Associação, sob coordenação de duas docentes do Departamento de Serviço Social. A dinâmica das reuniões desenvolveu-se da seguinte maneira: organização das cadeiras no formato de um círculo/roda, para 
ANAIS CBCS 2019 | 3 a 5 de outubro de 2019 | Centro Universitário Santo Agostinho - Teresina - PI

que todos se vejam e estejam em situação de igualdade; acolhida inicial; abordagem de um tema disparador da "conversa"; problematização e interação grupal; síntese; lanche.

\section{RESULTADOS E DISCUSSÃO}

Ao analisar a literatura das políticas sociais, sobretudo aquela focada na política de assistência social a qual passa, a partir do Sistema Único de Assistência Social - SUAS, a ter a matricialidade no grupo familiar, identificou-se que Mioto (2010) sinaliza para o predomínio de duas tendências, uma familista e a outra protetiva. A primeira, orientada pelo ideário neoliberal, postula a centralidade da família "apostando na sua capacidade imanente de cuidado e proteção" (p. 56), devendo arcar com o principal ônus do bem-estar de seus integrantes, sendo a esfera principal da provisão de bem-estar. De outra maneira, a perspectiva protetiva, correlaciona a capacidade de produção de cuidado e proteção social da família à "proteção que lhe é garantida pelas políticas públicas" (p. 57), o que, como pode ser visualizado historicamente, ocorreu de maneira precária no País. Destarte, Mioto (2015) ao adensar a análise sobre as contradições da política social centrada na família, no contexto brasileiro, indica a crescente tendência ao fortalecimento do familismo.

O que se observa nas tendências sinalizadas é uma forte inclinação, ora para a desassistência estatal na provisão de proteção social à família, com consequente sobrecarga familiar, em um contexto em que o sistema capitalista ruma para o desemprego estrutural e a família, para intensas mudanças sociodemográficas, tais como: envelhecimento das chefias; crescimento do número de famílias sob responsabilidade feminina; diminuição no tamanho do grupo familiar; crescente empobrecimento e supressão de direitos sociais, que repercutem sobremodo na sua dinâmica interna.

A inserção da mulher no mercado de trabalho, assim como inovações como o Estatuto da Criança e Adolescentes, assim como a Lei Maria da Penha e o Estatuto do Idoso trouxeram novas questões, de difícil compreensão e equacionamento no âmbito doméstico e nas interações cotidianas no âmbito familiar e comunitário. 
ANAIS CBCS 2019 | 3 a 5 de outubro de 2019 | Centro Universitário Santo Agostinho - Teresina - PI

De outro modo, observa-se que em conjunturas ou contextos favoráveis à ampliação de direitos e alargamento de políticas de proteção social, sobretudo no Brasil, houve pouco fomento ao protagonismo familiar, embora inscrito como princípio da política de assistência social e de saúde/saúde mental. Nesse sentido, a família foi mais instada a se comportar como mera consumidora dos serviços e muitas vezes "culpabilizada"/responsabilizada pelas mazelas sociais em que se situa ou seus membros.

No escopo do projeto em tela, a perspectiva que orienta as autoras é voltada para a afirmação das ações estatais em prol da garantia de políticas universalistas e afirmadoras da cidadania e do crescente processo de fortalecimento da cidadania, sobretudo da família e dos familiares, como esfera de conquista, que tem início com o acesso a informação qualificada e que permita ativar as forças sociais em prol de ações conscientemente orientadas para intensificar a solidariedade social, através da ação entre pares, ou seja, pessoas que vivenciam situações semelhantes e pode usar sua experiência para, ao compartilhar com seus iguais, construir modos de agir que permitam sair do isolamento social e criar um sentimento de pertencimento gerador de ações coletivas, em prol da promoção em saúde mental e de um ativismo social agregador de valores que rompam com o individualismo. Nesse diapasão, o foco das ações recai sobre a família.

Minayo (1999) define a família como uma organização social complexa, onde, simultaneamente, se vivem relações primárias e se constroem processos identificatórios e de pertencimento. É um espaço onde se definem papeis sociais de gênero, cultura de classe e onde as bases do poder são reproduzidas. É também o espaço da política entrelaçada no cotidiano das pessoas, nas discussões de pais e filhos, nas decisões sobre o futuro, dessa forma, é o espaço do afeto, do conflito e das contradições.

Bruschini (1989) conceitua família como:

[...] um grupo social composto de indivíduos diferenciados por sexo e por idade, que se relacionam cotidianamente, gerando uma complexa e dinâmica trama de emoções [...]. A sexualidade, a reprodução, a socialização são esferas potencialmente geradoras tanto de relações prazerosas quanto conflituosas. A divisão interna de papeis pode ser a expressão de importantes relações de dominação e submissão na medida em que configura uma distribuição de privilégios, direitos e deveres dentro do grupo (BRUSCHINI, 1989, p.13). 
ANAIS CBCS 2019 | 3 a 5 de outubro de 2019 | Centro Universitário Santo Agostinho - Teresina - P

Mioto (1997) afirma que, prioritariamente, a família não é o lugar somente de felicidade. Essa ideia surge com o ocultamento do caráter histórico da família, isto é resultado de uma ideologia que foi fortalecida entre fatos naturais e família (casamento, nascimento, morte) e pelo envolvimento afetivo que ocorre entre seus membros, minimizando a indiferença de uma sociedade industrial, cada vez mais materialista e desumanizada.

Rosa (2003) aponta que a família deve ser vista como ator social que constrói, configura e integra a realidade social, através de sua resposta em relação à saúde mental e à dependência ao álcool e outras drogas. Ou seja, a família cria diferentes ligações com o meio social, econômico e político, e constrói respostas que irão influenciar na construção da sua visão de ser humano e de mundo, nas relações sociais a serem estabelecidas e em seu posicionamento diante das diferentes expressões da questão social.

$\mathrm{Na}$ abordagem do consumo de álcool e outras drogas, a experiência circunscreveu a perspectiva posta pela lei no 11.343/2006 que prevê ações orientadas pela redução de danos, assim como fundamentadas em ações de prevenção e promoção em saúde, buscando redirecionar perspectivas centradas na substância e nas ações sobre a pessoa com um padrão de consumo dependente.

A promoção em saúde está relacionada com a promoção de qualidade de vida e a redução de vulnerabilidade e riscos relacionados aos seus determinantes e condicionantes - modos de viver, condições de trabalho, habitação, ambiente, educação, lazer, cultura, acesso a bens e serviços essenciais (BRASIL, 2010).

Promover saúde que é também educar para autonomia, na perspectiva freiriana, ao trabalhar com a mobilização comunitária, atuar no fortalecimento da ação comunitária, compartilhar saberes técnicos e saberes populares e criar condições para a construção de estratégias que têm se mostrado eficazes na abordagem dos problemas de saúde (BRASIL, 2002).

Com essas premissas, tem se construído a lógica, o projeto de extensão "Ativar a potência da família na promoção em saúde mental", cujas ações do projeto foram iniciadas em março de 
ANAIS CBCS 2019 | 3 a 5 de outubro de 2019 | Centro Universitário Santo Agostinho - Teresina - PI

2019 e, desde então, realizam-se atividades em grupos com famílias, mais precisamente, alguns familiares representantes, comumente as mulheres do grupo, todas as quartas-feiras.

Cada encontro girou em torno de um tema. Os temas iniciais foram propostos pelas coordenadoras e trataram: da apresentação do projeto; normas de convivência; e assuntos que giraram em torno do adensamento de temas como: família no contexto contemporâneo; direito da e na família; família e políticas públicas. No decorrer do desenvolvimento das ações, os participantes sugeriram temas vinculados à: gravidez na adolescência; depressão na adolescência; como superar conflitos familiares; direitos da criança; separação; drogas; desemprego.

Inicialmente havia um número significativo de homens participando ativamente do grupo, mas, logo em seguida observou-se a retirada dos homens desse cenário, à medida que os temas ficavam cada vez mais vinculados às questões familiares. Nesse sentido, observa-se a permanência de valores que colocam as mulheres como as principais responsáveis pela família e suas questões. Logo, as próprias mulheres sugeriram um nome para o grupo: "Papo de mulher", o que reforça a tendência crescente do protagonismo das mulheres e as dificuldades de engajamento dos homens nas questões familiares, que a elas delega.

A quantidade de participantes tem girado em uma média de 8 a cada encontro, o que permite que todas participem e ao mesmo tempo, possibilita um olhar mais atento para aquelas mais tímidas ou que estejam com alguma dificuldade no momento.

O grupo é composto majoritariamente por pessoas que se encontram na meia idade, estando em uma fase consolidada do curso de vida familiar, sendo a maioria casada. Metade do grupo é de mulheres branca e a outra parda, o que bem representa as diferenças étnico-raciais da realidade brasileira e até mesmo as desigualdades sociais, haja vista a maioria das mulheres pardas terem família com desenho monoparental, por elas chefiadas, tendo havido, em várias situações, gravidez na adolescência e trabalho infantil.

Por sua vez, observou-se que as mulheres brancas, predominantemente, seguiram o script traçado pela sociedade moderna, ou seja, namoraram, se casaram e tiveram filhos em seguida. A metade iniciou a vida de casada morando com a mãe ou a sogra. Nesse contexto, casar e ter uma 
ANAIS CBCS 2019 | 3 a 5 de outubro de 2019 | Centro Universitário Santo Agostinho - Teresina - PI

casa própria passou a se configurar uma aspiração que foi conquistada pela maioria. Contudo, há algumas avós que cuidam diretamente dos netos e outras mães que contam com o apoio financeiro da avó, por exemplo, para pagamento do colégio da filha, o que tem impactado na direção da condução da educação, pois a avó interfere, para que a neta seja uma estudante profissional, barrando ações da mãe no sentido de que a filha possa contribuir com algumas tarefas domésticas em torno do que usou ou sujou no espaço doméstico. Tal fato, bem ilustra como os conflitos familiares, sobretudo entre as pessoas adultas, recaem na educação, criação e direcionamento das crianças. Mas observou-se ainda o predomínio da subordinação das mulheres na relação conjugal, com parco envolvimento dos homens no trabalho doméstico e dificuldades em negociar sua participação nessa seara, tendo as mulheres que tomar cuidado, inclusive nas palavras que selecionam para convidá-los a tal engajamento, para não parecer que estão "mandando".

A análise do conflito nas relações familiares, no geral, foi percebida inicialmente como negativo, mas, a ação grupal possibilitou mostrar que o conflito também é elemento importante para trazer novos elementos para indagar o grupo e fazê-lo mudar, se repensar e repactuar visões de mundo ou relações.

Um momento que contou com maior participação dos homens foi em uma homenagem realizada em função do dia dos pais, onde foi discutido no grupo sobre "paternagem", estabelecendo a diferenciação entre esta e a paternidade. Esta última entendida como a dimensão biológica e jurídica, enquanto a paternagem é uma construção histórica, no processo de se construir como pai e que vem ganhando mais centralidade nos dias atuais, quando os homens vêm assumindo um papel de pai mais participante. Houve marcante participação dos presentes, que prestaram depoimentos sobre as vivências com seus pais e como ocorreram mudanças positivas nos relacionamentos entre pai e filho nos dias de hoje, em que relataram maior proximidade e novas responsabilidades que assumiram enquanto pais. Foi interessante observar a presença de um pai que era integralmente responsável pelo cuidado da filha, que se autoidentificou como "pai solteiro" - papel este tradicionalmente assumido pela figura feminina. Todavia, também nesta data estiveram presentes mulheres representando os pais dos seus filhos, pela ausência de uma figura 
ANAIS CBCS 2019 | 3 a 5 de outubro de 2019 | Centro Universitário Santo Agostinho - Teresina - PI

paterna presente. Tal presença-ausência, faz questionar ainda como essa mulher lida com a ausência da figura do pai na dinâmica familiar.

Assim, as reuniões possibilitaram também a observação das diferentes configurações familiares, como monoparental feminina - com a mãe ou avó responsável pelo cuidado dos filhos/netos - monoparental masculina, famílias extensas, nuclear, reconstituída, dentre outros.

\section{CONSIDERAÇÕES FINAIS/CONCLUSÕES}

O desenvolvimento das ações do projeto procurou ativar o protagonismo da família e ampliar sua competência social, através de ações grupais e fomento à circulação de saberes e intercâmbios comunitários. Apesar da presença de alguns homens em determinados encontros, é um grupo de mulheres que sustenta o grupo com sua participação frequente e o principal foco de debate gira em torno de conflitos familiares, circunscrevendo desigualdades de gênero (sobretudo conjugal) e questões intergeracionais, envolvendo a dinâmica entre mães e filhas, avós e netas e cônjuges. As discussões giraram em torno de como são geridos os conflitos, na perspectiva de construção de novos processos interativos, mediados pelo respeito, compreensão de limites e possibilidades.

Nesse sentido, o projeto de extensão "Ativar a potência da família na promoção em saúde mental" apresenta-se como inovador ao desenvolver ações em um território de vulnerabilidades na cidade de Teresina, realizando atividades de promoção à saúde mental de famílias que moram na região da Vila Ferroviária, contribuindo ao preencher uma lacuna assistencial e teórica junto a esse grupo de famílias. Destaca-se ainda a relevância do projeto de extensão no fortalecimento do papel social da universidade pública de transformar a realidade e melhorar a qualidade de vida da sociedade.

\section{REFERÊNCIAS}

BRASIL. Ministério da Saúde. Secretaria de Vigilância em Saúde. Secretaria de Atenção à Saúde. Política Nacional de Promoção da Saúde. 3. ed. Brasília: Ministério da Saúde, 2010. 60 p. (Série B. Textos Básicos de Saúde) (Série Pactos pela Saúde 2006; v. 7) 


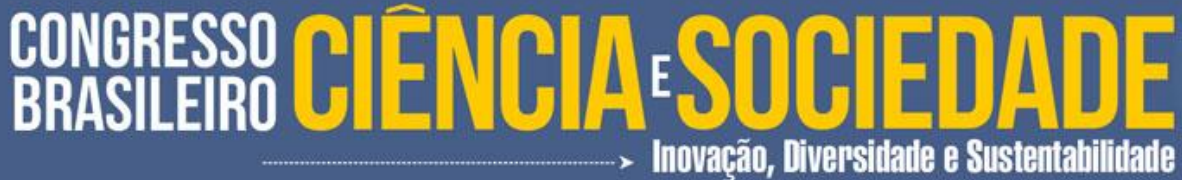

ANAIS CBCS 2019 | 3 a 5 de outubro de 2019 | Centro Universitário Santo Agostinho - Teresina - P

. Ministério da Saúde. Política Nacional de Promoção Da Saúde (Documento para discussão) Brasília, 2002.

FREIRE, P. Pedagogia do oprimido. 17ạ ed. Rio de Janeiro: Paz e Terra, 1987.

Fórum de Pró-Reitores das Instituições Públicas de Educação Superior Brasileiras (FORPROEX). Política Nacional de Extensão Universitária. Manaus - AM, Maio de 2012

MINAYO, M. C. O desafio do conhecimento: pesquisa qualitativa em saúde. 4ạ ed. São Paulo: Hucitec: Rio de Janeiro: Abrasco, 1996.

MIOTO, Regina Célia Tomaso. A família como referência nas políticas públicas: dilemas e tendências. P. 51-66. In: TRAD, L. Família contemporânea e saúde: significados, práticas e políticas públicas. Rio de Janeiro: Fiocruz, 2010.

; PRÁ, K. R. D. Serviços sociais e responsabilização da família: contradições da política social brasileira. P. 147-178. In: MIOTO, R.C. T.; CAMPOS, M.S.; CARLOTO, C. M. (Orgs.). Familismo direitos e cidadania: contradições da política social. São Paulo: Cortez, 2015.

ROSA, L.C.S. Transtorno mental e o cuidado na família. São Paulo: Cortez, 2003.

UNIVERSIDADE FEDERAL DO PIAUÍ. Regulamenta o cadastro, o acompanhamento e a avaliação de Programas e Projetos de Extensão, no âmbito da UFPI. Resolução № 085/18, de 15 de maio de 2018, Teresina. 